\title{
Simulação do Caminhamento da Água da Chuva e Herbicidas em Palhadas Utilizadas em Sistemas de Plantio Direto ${ }^{1}$
}

\author{
Simulation of Rain Wetting Dynamics and Herbicide Movement in Different Straws Used under \\ No-Tillage System
}

MACIEL, C.D.G. ${ }^{2}$ e VELINI, E.D. ${ }^{3}$

\begin{abstract}
RESUMO - Um experimento foi conduzido no NuPAM/FCA/UNESP, Botucatu-SP, objetivando avaliar a dinâmica de retenção de água e o caminhamento de um traçante (simulando um herbicida) em diferentes coberturas mortas. Os tratamentos foram constituídos pelo monitoramento do traçante FD\&C-1 pulverizado sobre coberturas mortas de cevada, trigo, aveia-preta colhida, aveia-preta rolada, azevém, milheto e capim-braquiária, nas quantidades de $3.000,6.000$ e $9.000 \mathrm{~kg} \mathrm{ha}^{-1}$, antes e após simulação de chuvas. As repetições constituíramse de oito conjuntos de PVC + funil + béquer com palha, onde, através da chuva lixiviada pelas palhadas e do peso dos suportes de PVC, foram estimadas a retenção e transposição da água, assim como quantificado o traçante extraído, através de procedimentos espectrofotométricos. Os diferentes tipos de resíduos culturais mostraram-se similares quanto à retenção da água da chuva, ocorrendo uniformização entre os primeiros 7,5 e $15 \mathrm{~mm}$ de precipitação. A formação de "pontos secos" associados a "canais preferenciais de escorrimento" induziu menor capacidade de embebição e retenção da água das chuvas pelas palhadas. As máximas capacidades médias de retenção da chuva pelas coberturas foram de 1,22, 1,99 e $2,59 \mathrm{~mm}$ para $3.000,6.000$ e $9.000 \mathrm{~kg}$ de matéria seca ha ${ }^{-1}$, respectivamente. As precipitações iniciais entre 10 e $20 \mathrm{~mm}$ foram fundamentais para o molhamento uniforme das palhadas e carregamento do traçante até o solo, independentemente do tipo e da quantidade de palha. Esse comportamento indica ser viável a utilização de programas similares de controle de plantas daninhas para diferentes tipos e quantidades de palha em sistemas de plantio direto.
\end{abstract}

Palavras-chave: cobertura morta, precipitação, traçante FD\&C-1.

\begin{abstract}
An experiment was conducted at NuPAM/FCA/UNESP, Botucatu-SP, Brazil, to evaluate the dynamics of water retention and the path of a tracer (simulating a herbicide) in different crop residues. The treatments were constituted by monitoring of the tracer FD\&C-1 on mulches of barley (Hordeum vulgare), perennial ryegrass (Lolium multiflorum), wheat (Triticum aestivum), harvested oat (Avena strigosa), rolled oat (A. strigosa), corn (Zea mays), millet (Penisetum americanum) and Surinam grass (Brachiaria decumbens), in the following amounts: 3000,6000 and $9000 \mathrm{~kg} \mathrm{ha}^{-1}$, before and after rain simulation. The replications were eight sets of PVC + Funnel + Becker with straw, with water retention and transposition being estimated and the extracted tracer quantified through the rain leached in the straws and the PVC support weight by using spectrophotometric procedures. The different crop residues were found to be similar regarding rainwater retention, with uniformity occurring between the first 7.5 and $15 \mathrm{~mm}$ of rain. The formation of "dry points" associated to "preferential running off channels" induced the smaller capacity of absorption and retention of the rain water by the straws. The maximum mean capacities of rain retention by the straws were 1.22; 1.99 and $2.59 \mathrm{~mm}$ for 3,000, 6,000 and $9,000 \mathrm{~kg}$ of dry matter ha-1, respectively. The initial precipitations between 10 and $20 \mathrm{~mm}$ were crucial for the uniform wetting of the straws and wash off of the tracer to the soil, regardless of type and amount of straw. This behavior indicates the viability of using similar programs of weed control for different types and amounts of straw under no-tillage systems.
\end{abstract}

Key words: mulch, wetting dynamics, tracer FD\&C-1.

Recebido para publicação em 27.7.2004 e na forma revisada em 5.9.2005.

Parte da dissertação de mestrado do primeiro autor apresentada à UNESP/FCA, Botucatu-SP.

2 Doutorando em Agricultura do Dep. de Produção Vegetal - FCA/UNESP, Caixa Postal 237, 18603-970 Botucatu-SP. ${ }^{3}$ Professor Assistente, Dr. do Dep. de Produção Vegetal - UNESP/FCA, Caixa Postal 237, 18603-970 Botucatu-SP. 


\section{INTRODUÇÃO}

Nos últimos anos tem-se observado uma rápida expansão mundial de áreas com culturas implantadas sobre algum tipo de palhada utilizada como cobertura morta. No Brasil, entre exemplos típicos, pode-se mencionar o cultivo mínimo em áreas de reflorestamento, com manutenção da serrapilheira sobre o solo, o sistema de produção de cana crua e, com maior adoção, o plantio direto de culturas anuais. Segundo Sade (2000), a expansão da área cultivada em plantio direto no Brasil foi da ordem de 1,00 milhão de hectares na safra de 90/91 para 13,37 milhões na safra de 98/99. Nesse aspecto, a difusão positiva do sistema em território brasileiro contribuiu para ampliar as estimativas de adoção em aproximadamente 58 milhões de hectares em todo o mundo (Derpsch, 2000).

Vários trabalhos destacam a importância da manutenção da palhada das culturas anteriores sobre a superficie do solo, alguns considerando que esse procedimento recupera a estrutura do solo, por aumentar o teor de matéria orgânica e, conseqüentemente, melhorar a sua atividade biológica; outros valorizam a redução da erosão pluvial pela absorção do impacto das gotas de chuva pela palhada, assim como o prolongamento na armazenagem da água da chuva em seu perfil, devido à menor evaporação (Meyer et al., 1970; Lopes et al., 1987; Lombardi Neto et al., 1988; Alves et al., 1995). Em contraste, quanto às plantas daninhas, ainda são restritos os trabalhos que procuram avaliar os efeitos das coberturas mortas sobre a sua ocorrência e/ou controle, assim como são poucas as informações sobre a dinâmica de herbicidas e da água das chuvas em coberturas mortas (Lowder \& Weber, 1979; Baumam \& Ross, 1983; Ghadiri et al., 1984; Banks \& Robinson, 1984, 1986; Sigua et al., 1993; Rodrigues, 1993; Dao, 1995; Green et al., 1995; Locke \& Bryson, 1997; Rodrigues et al., 1997, 2000; Martins et al., 1999; Correia \& Durigan, 2004).

$\mathrm{Na}$ maioria das vezes, os benefícios das coberturas em relação às alterações nas comunidades infestantes têm sido atribuídos aos compostos alelopáticos, ainda não isolados e identificados, e aos efeitos físicos, que não podem ser desconsiderados, uma vez que as espécies infestantes, em geral, apresentam dormência ou algum tipo de controle de germinação (Egley \& Duke, 1985; Velini \& Negrisoli, 2000). No entanto, nesses sistemas de produção podem ocorrer grandes variações na quantidade e na composição da cobertura morta, que pode ou não suprimir a germinação da comunidade infestante, bem como influenciar a dinâmica de herbicidas aplicados sobre a palhada, nas ocasiões em que o controle se faz necessário.

Nesse sentido, a manutenção das coberturas mortas sobre a superficie do solo pode, simultaneamente, reduzir o potencial de infestação da comunidade infestante, como também dificultar o desempenho de herbicidas, uma vez que os principais componentes da dinâmica de herbicidas sobre a palha em áreas onde há manutenção de resíduos culturais na superficie do solo são a transposição do produto através dela e a própria dinâmica de molhamento e lavagem da palha pela água das chuvas.

Dessa forma, o trabalho teve como objetivo avaliar a dinâmica de molhamento e o caminhamento de um traçante (simulando herbicidas) em diferentes coberturas mortas, por meio de simulação de chuva.

\section{MATERIAL E MÉTODOS}

O experimento foi desenvolvido no Núcleo de Pesquisas Avançadas em Matologia (NuPAM), pertencente ao Departamento de Produção Vegetal da Faculdade de Ciências Agronômicas, UNESP, Botucatu-SP. Os tratamentos foram constituídos pelo monitoramento da dinâmica de água das chuvas e do traçante FD\&C-1 (azul-brilhante), pulverizado sobre coberturas mortas de cevada (Hordeum vulgare), trigo (Triticum aestivum), aveia-preta colhida e rolada (Avena strigosa), azevém (Lolium multiflorum), milheto (Penisetum americanum) e capim-braquiária (Brachiaria decumbens), nas quantidades de $3.000,6.000$ e $9.000 \mathrm{~kg} \mathrm{ha}^{-1}$, antes e após simulação de lâminas de chuvas.

Um equipamento foi desenvolvido para execução do trabalho, constituído por duas barras independentes, uma responsável pelo sistema de simulação de chuva e outra pela pulverização do traçante, simulando aplicação 
de herbicida (Figura 1). As barras do equipamento foram tracionadas com auxílio de um motor elétrico, utilizando-se velocidades constantes e previamente determinadas. As gotas de chuva artificial foram geradas por pontas de pulverização de alta vazão, modelo TK-SS-20, espaçadas de 0,50 m, com pressão

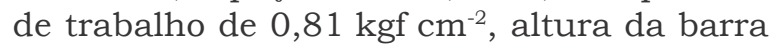
de 1,45 m em relação à superfície das unidades experimentais e velocidade de deslocamento de $0,0526 \mathrm{~m} \mathrm{~s}^{-1}$. Essas especificações proporcionaram a produção de gotas artificiais de chuva com diâmetro mediano volumétrico (DMV) de aproximadamente 1.140 micras, conforme informações do fabricante (Spraying Systems).

Para as pulverizações do traçante FD\&C-1 na concentração de 3.000 ppm foram utilizadas pontas XR11002-VS, espaçadas de 0,5 m, localizadas a $50 \mathrm{~cm}$ de altura em relação à superficie das unidades experimentais, pressão de $2,1 \mathrm{kgf} \mathrm{cm}^{-2}$, velocidade de $1,0 \mathrm{~m} \mathrm{~s}^{-1}$ e consumo de calda de $200 \mathrm{~L} \mathrm{ha}^{-1}$. Esse procedimento foi efetuado aproximadamente 12 horas antes do início das simulações das lâminas de chuvas.
A possibilidade do estudo conjunto da dinâmica de molhamento e caminhamento do traçante nas diferentes palhadas foi proveniente de informações preliminares (Paladini, 2000), que garantem a não-alteração das características físico-químicas da água da chuva simulada pela presença do traçante. Dentre essas características destacam-se a alta solubilidade em água, a não-volatilidade, as propriedades aniônicas de modo similar a vários herbicidas de ação pré-emergente e, principalmente, a não-alteração na tensão superficial da solução quando dissolvido em água.

A quantidade de traçante FD\&C-1 que conseguiu atingir a superficie do funil, atravessando as diferentes camadas de palha apenas com o advento da pulverização, foi estimada através da lavagem das paredes internas do funil, com posterior leitura da solução recuperada, por meio de espectrofotômetro de feixe duplo, modelo Cintra 20, operando com $10 \mathrm{~mm}$ de caminho ótico. De forma similar, desenvolveu-se o estudo da lixiviação do traçante FD\&C-1 retido na palha, após as simulações das chuvas.
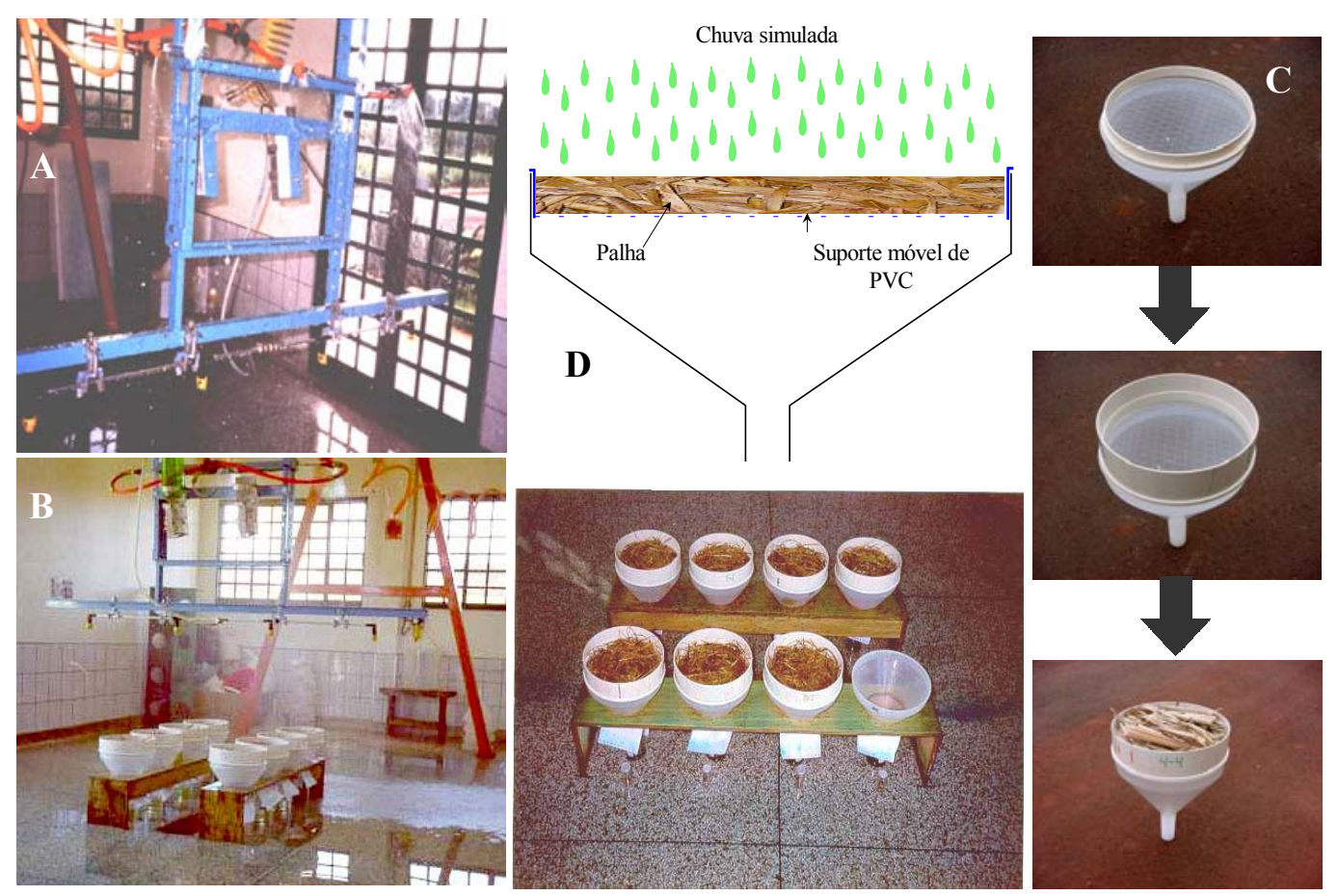

Figura 1 - Configuração do simulador de chuva e pulverização em sala de ambiente fechado (A e B), representação esquemática das unidades experimentais (C) e procedimentos de lavagem das palhadas (D). NuPAM, UNESP/FCA. Botucatu-SP, 2001. 
Para cada cobertura morta, nas três quantidades estudadas, foram utilizadas oito repetições, constituídas de conjuntos de PVC + funil + béquer com palha, submetidos à simulação de dez lâminas de chuva (Figura 1). O procedimento de rotina de simulação de chuva do experimento foi inicialmente constituído pela organização, identificação e pesagem da palhada colocada nos suportes móveis de PVC do sistema de lavagem. Em seguida, através da chuva lixiviada pelas palhadas e do peso dos suportes de PVC com palha, foram estimadas a retenção e transposição da água para as coberturas, assim como quantificado o traçante extraído, utilizando procedimentos espectrofotométricos.

Na Tabela 1, um esquema didático caracteriza os valores das precipitações acumuladas referentes às dez lâminas efetivas de chuvas simuladas para cada quantidade e tipo de palha, sendo seus valores considerados de forma acumulada. O procedimento de aferição das chuvas (branco) constituiu-se da simulação de uma lâmina de água sobre os funis sem os suportes móveis com palha. Para as cinco primeiras simulações, cada lâmina efetiva foi constituída pelo deslocamento completo da barra de aplicação sobre todas as unidades experimentais. A partir da sexta lâmina simulada, as lâminas efetivas passaram a ser constituidas por cinco consecutivos deslocamentos da barra.

Os dados referentes às lâminas de água retidas na palha e a concentração do traçante na água das chuvas foram convertidos para milimetro $(\mathrm{mm})$ de chuva e microgramas $(\mu \mathrm{g})$ de FD\&C-1, respectivamente, sendo posteriormente ajustados segundo o modelo de Mitscherlich $\left(\mathrm{Y}=\mathrm{a}^{*}\left(1-10^{\wedge}-\mathrm{c}^{*}(\mathrm{~b}+\mathrm{x})\right)\right)$. As letras "a", "b" e "c" do modelo representam os parâmetros da equação, sendo "a" a assíntota máxima da curva (estabelecida em 100\%), ou seja, a lâmina máxima retida pela palhada; "b" o deslocamento lateral da curva (estabelecido em $0 \%$ ); e "c" a concavidade da curva, o que indica a velocidade ou eficiência de embebição da água da chuva pela palha e/ou saída de FD\&C-1 desta. Adotou-se valor "O" para o parâmetro "b", pois as curvas necessariamente passam pela origem. Na equação de Mitscherlich, a letra " $x$ " corresponde às lâminas de chuva simuladas da precipitação $(\mathrm{mm})$ e "y" à lâmina de chuva retida $(\mathrm{mm})$ ou lixiviada através da palha (\%), assim como a quantidade de FD\&C-1 recuperado na água de chuva lixiviada $(\mu g)$.

Tabela 1 - Procedimentos de interpretação da disposição das lâminas efetivamente simuladas no experimento. NuPAM, UNESP/FCA. Botucatu-SP, 2001

\begin{tabular}{|c|c|c|}
\hline Lâmina efetiva & $\begin{array}{c}\text { № de deslocamentos } \\
\text { da barra }\end{array}$ & $\begin{array}{l}\text { Valores referentes às lâminas acumuladas } \\
\text { Lâmina efetiva }_{\mathrm{i}}=\left(\mathrm{PU}_{\mathrm{i}}-\mathrm{PS}\right)+\left({ }^{10} \Sigma_{\mathrm{i}=1} \mathrm{VA}\right)\end{array}$ \\
\hline BRANCO $^{1 /}$ & $1 \mathrm{x}$ & - \\
\hline 1'- Lâmina & $1 \mathrm{x}$ & Lâmina efetiva ${ }_{1}=\left(\mathrm{PU}_{1}-\mathrm{PS}\right)+\mathrm{VA}_{1}$ \\
\hline $2^{\text {a }}$ Lâmina & $1 \mathrm{x}$ & Lâmina efetiva ${ }_{2}=\left(\mathrm{PU}_{2}-\mathrm{PS}\right)+\mathrm{VA}_{1}+\mathrm{VA}_{2}$ \\
\hline 3- Lâmina & $1 \mathrm{x}$ & Lâmina efetiva $3=\left(\mathrm{PU}_{3}-\mathrm{PS}\right)+\mathrm{VA}_{1}+\mathrm{VA}_{2}+\mathrm{VA}_{3}$ \\
\hline BRANCO & $1 \mathrm{x}$ & - \\
\hline 4- Lâmina & $1 \mathrm{x}$ & Lâmina efetiva ${ }_{4}=\left(\mathrm{PU}_{4}-\mathrm{PS}\right)+\mathrm{VA}_{1}+\mathrm{VA}_{2}+\mathrm{VA}_{3}+\mathrm{VA}_{4}$ \\
\hline 5- Lâmina & $1 \mathrm{x}$ & Lâmina efetiva $=\left(\mathrm{PU}_{5}-\mathrm{PS}\right)+\mathrm{VA}_{1}+\ldots+\mathrm{VA}_{5}$ \\
\hline $6^{\text {a }}$ Lâmina & $5 x$ & Lâmina efetiva $6=\left(\mathrm{PU}_{6}-\mathrm{PS}\right)+\mathrm{PA}_{1}+\ldots+\mathrm{PA}_{6}$ \\
\hline BRANCO & $1 \mathrm{x}$ & 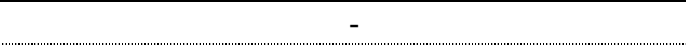 \\
\hline 7" Lâmina & $5 x$ & Lâmina efetiva $7=\left(\mathrm{PU}_{7}-\mathrm{PS}\right)+\mathrm{VA}_{1}+\ldots+\mathrm{VA}_{7}$ \\
\hline 8' Lâmina & $5 x$ & Lâmina efetiva ${ }_{8}=\left(\mathrm{PU}_{8}-\mathrm{PS}\right)+\mathrm{VA}_{1}+\ldots+\mathrm{VA}_{8}$ \\
\hline 9- Lâmina & $5 x$ & Lâmina efetiva $_{9}=\left(\mathrm{PU}_{9}-\mathrm{PS}\right)+\mathrm{VA}_{1}+\ldots+\mathrm{VA}_{9}$ \\
\hline BRANCO & $1 \mathrm{x}$ & 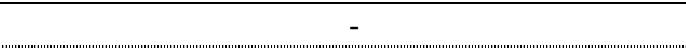 \\
\hline $10^{\mathrm{a}}$ Lâmina & $5 x$ & Lâmina efetiva $10=\left(\mathrm{PU}_{10}-\mathrm{PS}\right)+\mathrm{VA}_{1}+\ldots+\mathrm{VA}_{10}$ \\
\hline
\end{tabular}

1/ BRANCO = procedimento de aferição do equipamento.

$\mathrm{PU}_{\mathrm{i}}=$ peso da água da lâmina de chuva que ficou retida na camada de palha; PS = peso da palha seca antes da simulação das lâminas de chuva; e VA = volume ou massa da água que transpôs a palha e foi coletada pelo funil no amostrador. 


\section{RESULTADOS E DISCUSSÃO}

Na Figura 2 estão representadas as equações de retenção, segundo modelo de Mitscherlich, entre as lâminas de água retidas e lâminas de chuva aplicadas sobre coberturas mortas, constituídas por 3.000, 6.000 e $9.000 \mathrm{~kg}$ de matéria seca ha ${ }^{-1}$. Por meio dessas informações, observa-se que as lâminas de chuva retidas pelos diferentes tipos e quantidades de resíduos culturais apresentaram comportamentos bastante similares, sendo crescentes à medida que foi aumentada a quantidade da palhada estudada. De forma geral, o volume máximo de retenção da chuva para os diferentes tipos e quantidades de resíduos culturais ocorreu entre 7,5 e 15,0 mm de chuva simulada.

Conforme adequação do modelo de Mitscherlich (Figura 2), novas simulações de chuva a partir dos valores de máxima retenção mencionados não modificam o comportamento constante e estável da retenção da água, nos diferentes tipos e quantidades de cobertura. Os resultados das análises de regressão, dispostos na Tabela 2, evidenciam o ajuste satisfatório dos dados originais ao modelo de Mitscherlich, o que é comprovado pelos elevados coeficientes de determinação $\left(R^{2}\right)$ obtidos.

Na Tabela 2 pode-se constatar a relação inversa entre quantidade de resíduos culturais e velocidade de embebição da palha, assim como relação direta entre quantidade de resíduos culturais e assíntota máxima da curva de retenção, representada pela letra " $a$ " no modelo de Mitscherlich. Em contraste, na Figura 3 observa-se relação inversa entre o volume de chuva retido por unidade de matéria seca e as quantidades de cobertura morta por unidade de área.

A possivel justificativa para a menor retenção de água por unidade de matéria seca é a formação de "pontos secos" associados a "canais preferenciais de escorrimento" dentro das camadas de palha. Dessa forma, as maiores quantidades de resíduos culturais cobrindo a superficie do solo proporcionam a organização das partículas de palha com maior freqüência de "pontos secos". Conseqüentemente, a maior freqüência de "pontos secos" ou "canais preferenciais de escorrimento" induz a menor capacidade de embebição e retenção da água da chuva pela palhada.

Na Figura 4 e Tabela 3 estão representadas as curvas estimadas e os parâmetros das equações do modelo de Mitscherlich completo e simplificado para porcentagem de chuva retida ou lixiviada nos diferentes tipos e quantidades de resíduos culturais, observandose o comportamento para lâminas pequenas de chuva simulada. Os resultados comprovaram novamente a aproximação das curvas dos processos de retenção e lixiviação da chuva com o aumento dos pesos de matéria seca por hectare, ou seja, as curvas referentes a 6.000 e $9.000 \mathrm{~kg}$ de matéria seca ha ${ }^{-1}$ foram bastante
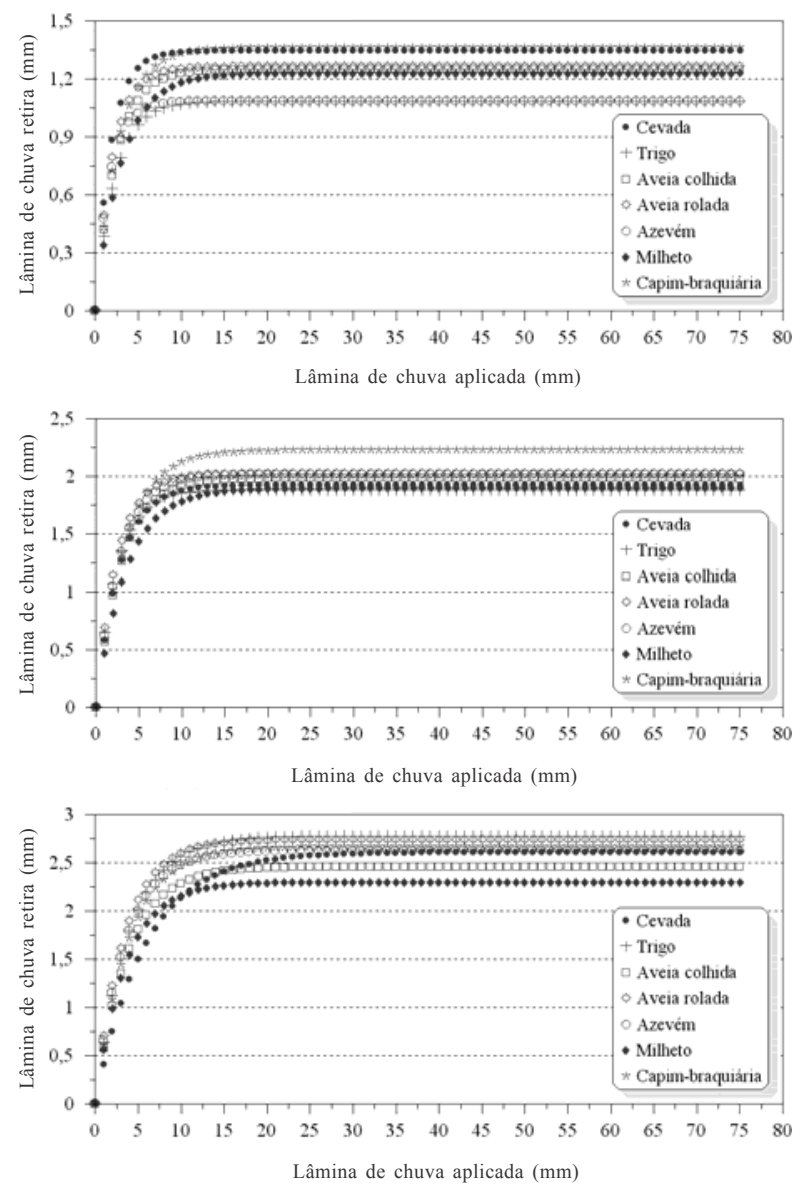

Figura 2 - Equações de regressão entre as lâminas de chuva retida em 3.000 (A), 6.000 (B) e 9.000 (C) kg de matéria seca ha ${ }^{-1}$ dos diferentes tipos de cobertura morta e lâminas de chuva aplicada artificialmente, utilizando-se o modelo de Mitscherlich.

Planta Daninha, Viçosa-MG, v. 23, p. 471-481, 2005 
similares entre si, mas distintas das curvas obtidas para a menor quantidade de palha.

Na Figura 5 encontram-se as análises de regressão da dinâmica de lixiviação do traçante FD\&C-1, simulando um herbicida, nos diferentes tipos e quantidades de palhadas. A adequação satisfatória do modelo de Mitscherlich aos dados originais proporcionou coeficientes de determinação bastante elevados (Tabela 4), oscilando entre 0,9758 e 0,9990, respectivamente. De modo geral, as maiores quantidades do traçante foram removidas pelos primeiros $10 \mathrm{~mm}$ de chuva; com mais $10 \mathrm{~mm}$ de chuva, totalizando $20 \mathrm{~mm}$, foi possivel remover praticamente todo o traçante de todos os tipos e quantidades de palhada. Contudo, a maior retenção do traçante pelas quantidades superiores de palha foi observada para os restos culturais de cevada, aveia rolada e capim-braquiária. Esse comportamento é evidenciado pelas menores assintotas horizontais (parâmetro "a" do modelo) observadas para 6.000 e $9.000 \mathrm{~kg}$ de palhada ha-1 (Tabela 4). Para as demais coberturas, as estimativas das quantidades totais de traçante foram próximas para todas as quantidades de palhada. Resultados semelhantes foram obtidos por Marin et al. (1978), Lamoreaux et al. (1993) e Fornarolli et al. (1998), trabalhando com palhadas de trigo, milho e aveia, submetidas a simulações de chuva de até $20 \mathrm{~mm}$, após efetuada pulverização de herbicidas em pré-emergência.

Ainda na Figura 5 e Tabela 4, observa-se que para $3.000 \mathrm{~kg}$ de matéria seca ha-1 a dinâmica de saída do traçante foi relativamente uniforme para todas as coberturas estudadas, ocorrendo acentuada diferença entre as culturas com o aumento da quantidade de palha. Todavia, deve-se destacar a elevada imobilização do traçante pelas coberturas de cevada (6.000 e $\left.9.000 \mathrm{~kg} \mathrm{ha}^{-1}\right)$ e aveia rolada $\left(6.000 \mathrm{~kg} \mathrm{ha}^{-1}\right)$, principalmente quando

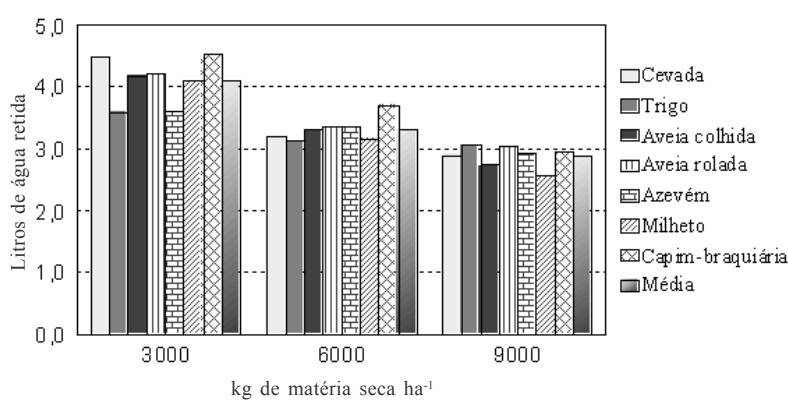

Figura 3 - Quantidade média de chuva retida por unidade de matéria seca das diferentes coberturas mortas estudadas.

Tabela 2 - Resultados das análises de regressão entre quantidade de chuva retida em 3.000, $6.000 \mathrm{e} 9.000 \mathrm{~kg}$ de matéria seca ha ${ }^{-1} \mathrm{e}$ lâmina de chuva aplicada artificialmente, utilizando-se o modelo de Mitscherlich. NuPAM, UNESP/FCA. Botucatu-SP, 2001

\begin{tabular}{|c|c|c|c|c|c|c|c|}
\hline \multirow[b]{2}{*}{ Modelo } & \multicolumn{7}{|c|}{$\mathrm{Y}=\mathrm{A}^{*}\left(1-10^{\wedge}-\mathrm{C}^{*}(\mathrm{~B}+\mathrm{X})\right)$} \\
\hline & Cevada & Trigo & Aveia colhida & Aveia rolada & Azevém & Milheto & $\begin{array}{c}\text { Capim- } \\
\text { braquiária }\end{array}$ \\
\hline & \multicolumn{7}{|c|}{$3.000 \mathrm{~kg} \mathrm{ha}^{-1}$ de resíduos culturais } \\
\hline \multirow{2}{*}{ Estimativa dos parâmetros } & A 1,3497 & 1,0795 & 1,2473 & 1,2617 & 1,0827 & 1,2288 & 1,3557 \\
\hline & C 0,2328 & 0,1900 & 0,1776 & 0,2145 & 0,2498 & 0,1403 & 0,1636 \\
\hline F Regressão & $8,46619 * *$ & $5,24497 * *$ & $6,93615^{* *}$ & $7,32746 * *$ & $5,46937 * *$ & $6,40114 * *$ & $8,11105^{*}$ \\
\hline \multirow[t]{2}{*}{$\mathrm{R}^{2}$} & 0,9064 & 0,9612 & 0,9230 & 0,9728 & 0,9690 & 0,9450 & 0,9442 \\
\hline & \multicolumn{7}{|c|}{$6.000 \mathrm{~kg} \mathrm{ha}^{-1}$ de resíduos culturais } \\
\hline \multirow{2}{*}{ Estimativa dos parâmetros } & A 1,9220 & 1,8726 & 1,9820 & 2,0180 & 2,0130 & 1,8932 & 2,2199 \\
\hline & $\mathrm{C} 0,1556$ & 0,1827 & 0,1458 & 0,1799 & 0,1587 & 0,1221 & 0,1316 \\
\hline F Regressão & $15,89549^{* *}$ & $15,73380 * *$ & $16,65646^{* *}$ & $18,15716^{* *}$ & $17,71049 * *$ & $14,55727 * *$ & $20,73614^{*}$ \\
\hline \multirow[t]{2}{*}{$\begin{array}{r}\mathrm{R}^{2} \\
\end{array}$} & 0,9195 & 0,9454 & 0,9580 & 0,9768 & 0,9487 & 0,9348 & 0,9686 \\
\hline & \multicolumn{7}{|c|}{$9.000 \mathrm{~kg} \mathrm{ha}^{-1}$ de resíduos culturais } \\
\hline \multirow{2}{*}{ Estimativa dos parâmetros } & A 2,6109 & 2,7667 & 2,4595 & 2,7343 & 2,6205 & 2,2955 & 2,6541 \\
\hline & $\mathrm{C} 0,1311$ & 0,1122 & 0,1153 & 0,1278 & 0,1251 & 0,1210 & 0,1116 \\
\hline F Regressão & $27,97735^{* *}$ & $31,04435^{* *}$ & $24,19174 * *$ & $30,63016^{* *}$ & $28,42753 * *$ & $21,28366 * *$ & $27,61885^{*}$ \\
\hline $\mathrm{R}^{2}$ & 0,9573 & 0,9603 & 0,9568 & 0,9882 & 0,9518 & 0,9555 & 0,9746 \\
\hline
\end{tabular}

** Significativo a $1 \%$ de probabilidade.

$\mathrm{Y}=$ lâmina de chuva retida na palha $(\mathrm{mm}) ; \mathrm{X}=$ lâmina de chuva aplicada $(\mathrm{mm}) ; \mathrm{A}=$ lâmina máxima de chuva retida pela palha; $\mathrm{B}=$ deslocamento lateral da curva (considerado valor igual a zero); e $\mathrm{C}=$ eficiência da velocidade de embebição da palhada. 
comparada com as coberturas de milheto (3.000, 6.000 e $9.000 \mathrm{~kg}$ de matéria seca ha-1), a qual permitiu a maior mobilização do traçante.
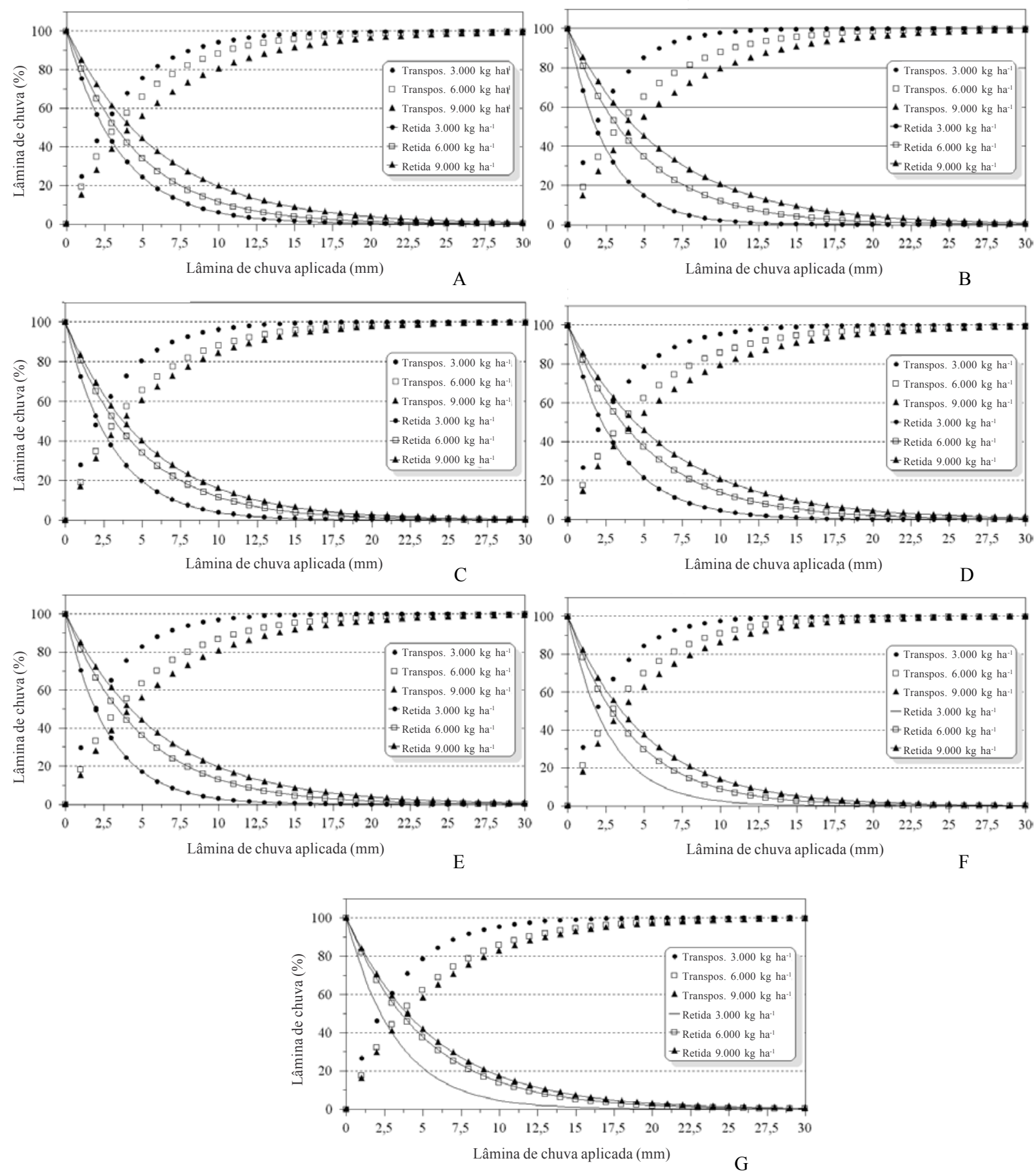

Figura 4 - Equações de regressão entre as lâminas de chuva (\%) que ficaram retidas ou transpuseram 3.000, 6.000 e $9.000 \mathrm{~kg}$ de matéria seca ha ${ }^{-1}$ e a lâmina de chuva aplicada artificialmente. Equações de regressão obtidas para as coberturas de cevada (A), trigo (B), aveia colhida (C), aveia rolada (D), azevém (E), milheto (F) e capim-braquiária (G), utilizando-se o modelo de Mitscherlich completo e simplificado. 
Tabela 3 - Resultados das análises de regressão entre as lâminas de chuvas (\%) que ficaram retidas ou transpuseram 3.000, 6.000 e $9.000 \mathrm{~kg}$ de matéria seca ha ${ }^{-1}$ e lâminas de chuva aplicada artificialmente, utilizando-se o modelo de Mitscherlich completo e simplificado. NuPAM, UNESP/FCA. Botucatu-SP, 2001

\begin{tabular}{|c|c|c|c|c|c|c|c|}
\hline \multirow[b]{2}{*}{ Modelo $^{\underline{1}}$} & \multicolumn{4}{|c|}{$\mathrm{Y}=\mathrm{A}^{*}\left(1-10^{\wedge}-\mathrm{C}^{*}(\mathrm{~B}+\mathrm{X})\right)$} & \multicolumn{3}{|c|}{$\mathrm{Y}=10^{\wedge} 2-(\mathrm{C}+\mathrm{X})$} \\
\hline & Cevada & Trigo & Aveia colhida & Aveia rolada & Azevém & Milheto & $\begin{array}{c}\text { Capim- } \\
\text { braquiária }\end{array}$ \\
\hline & \multicolumn{7}{|c|}{$3.000 \mathrm{~kg} \mathrm{ha}^{-1}$} \\
\hline Parâmetro estimado & C 0,12229 & 0,16509 & 0,14091 & 0,13412 & 0,15309 & 0,16013 & 0,13361 \\
\hline F Regressão & $77906,19^{* *}$ & $81797,78^{* *}$ & $79552,39^{* *}$ & $78991,84 * *$ & $80723,06^{* *}$ & $80455,49 * *$ & $78760,43^{* *}$ \\
\hline \multirow[t]{2}{*}{$\mathrm{R}^{2}$} & 0,9771 & 0,9677 & 0,9735 & 0,9967 & 0,9718 & 0,9601 & 0,9669 \\
\hline & \multicolumn{7}{|c|}{$6.000 \mathrm{~kg} \mathrm{ha}^{-1}$} \\
\hline Parâmetro estimado & C 0,09363 & 0,09180 & 0,09347 & 0,08530 & 0,08807 & 0,10418 & 0,08460 \\
\hline F Regressão & $70405,72^{* *}$ & $71598,18^{* *}$ & $69702,93 * *$ & $69072,35^{* *}$ & $69956,28^{* *}$ & $71629,87 * *$ & $68806,13^{* *}$ \\
\hline \multirow[t]{2}{*}{$\mathrm{R}^{2}$} & 0,9767 & 0,9774 & 0,9711 & 0,9757 & 0,9748 & 0,9680 & 0,9682 \\
\hline & \multicolumn{7}{|c|}{$9.000 \mathrm{~kg} \mathrm{ha}^{-1}$} \\
\hline Parâmetro estimado & C 0,07114 & 0,06891 & 0,08003 & 0,06822 & 0,07097 & 0,08545 & 0,07590 \\
\hline F Regressão & $62462,61 * *$ & $64021,17^{* *}$ & $65699,86^{* *}$ & $61972,07 * *$ & $64254,98^{* *}$ & $66809,15^{* *}$ & $63004,23^{* *}$ \\
\hline $\mathrm{R}^{2}$ & 0,9731 & 0,9684 & 0,9692 & 0,9680 & 0,9727 & 0,9684 & 0,9613 \\
\hline
\end{tabular}

** Significativo a $1 \%$ de probabilidade.

$\mathrm{Y}=$ lâmina de chuva retida ou que transpôs a palha $(\mathrm{mm}) ; \mathrm{X}=$ lâmina de chuva aplicada $(\mathrm{mm}) ; \mathrm{A}=$ lâmina máxima de chuva retida pela palha (valor considerado $100 \%$ ); $\mathrm{B}=$ deslocamento lateral da curva (valor considerado $0 \%$ ); e C = eficiência da velocidade de retenção ou lixiviação da água da chuva pela palha.

Tabela 4 - Resultados das análises de regressão entre quantidade do traçante FD\&C-1 recuperada em 3.000, 6.000 e $9.000 \mathrm{~kg}$ de matéria seca ha ${ }^{-1}$ de resíduos culturais e lâminas de chuva aplicada artificialmente, utilizando-se o modelo de Mitscherlich. NuPAM, UNESP/FCA. Botucatu-SP, 2001

\begin{tabular}{|c|c|c|c|c|c|c|c|}
\hline \multirow[b]{2}{*}{ Modelo $^{1 /}$} & \multicolumn{7}{|c|}{$\mathrm{Y}=\mathrm{A}^{*}\left(1-10^{\wedge}-\mathrm{C}^{*}(\mathrm{~B}+\mathrm{X})\right)$} \\
\hline & Cevada & Trigo & Aveia colhida & Aveia rolada & Azevém & Milheto & $\begin{array}{c}\text { Capim- } \\
\text { braquiária }\end{array}$ \\
\hline & \multicolumn{7}{|c|}{$3.000 \mathrm{~kg} \mathrm{ha}^{-1}$} \\
\hline \multirow{3}{*}{$\begin{array}{l}\text { Estimativa dos } \\
\text { parâmetros }\end{array}$} & A 2104,67 & 1965,47 & 1930,38 & 2092,54 & 2014,62 & 2263,14 & 2291,91 \\
\hline & В 0,759261 & 0,608156 & 0,427661 & 0,767566 & 0,553873 & 0,762392 & 0,780526 \\
\hline & $\mathrm{C} \quad 0,08270$ & 0,11541 & 0,11183 & 0,108102 & 0,12636 & 0,10391 & 0,08933 \\
\hline F Regressão & $11509135,7 * *$ & $10806617,7^{* *}$ & $10258719,1^{* *}$ & $12173928,9^{* *}$ & $11533974,3^{* *}$ & $13995917,6^{* *}$ & $13952326,6^{* *}$ \\
\hline \multirow[t]{2}{*}{$\mathrm{R}^{2}$} & 0,9895 & 0,9979 & 0,9960 & 0,9960 & 0,9981 & 0,9990 & 0,9964 \\
\hline & \multicolumn{7}{|c|}{$6.000 \mathrm{~kg} \mathrm{ha}^{-1}$} \\
\hline \multirow{3}{*}{$\begin{array}{l}\text { Estimativa dos } \\
\text { parâmetros }\end{array}$} & A 1751,25 & 1984,50 & 1979,68 & 1687,12 & 2068,78 & 2299,45 & 2148,17 \\
\hline & B $-0,05304$ & 0,167027 & 0,047019 & 0,133684 & 0,079189 & 0,359345 & 0,243457 \\
\hline & C 0,10340 & 0,07854 & 0,08827 & 0,10118 & 0,08737 & 0,06775 & 0,07123 \\
\hline F Regressão & $7975429,8^{* *}$ & $9751362,1 * *$ & $9747433,9^{* *}$ & $7485224,7 * *$ & $10829064,3^{* *}$ & $12279673,7 * *$ & $11082661,6^{* *}$ \\
\hline \multirow[t]{2}{*}{$\mathrm{R}^{2}$} & 0,9926 & 0,9988 & 0,9906 & 0,9957 & 0,9913 & 0,9822 & 0,9916 \\
\hline & \multicolumn{7}{|c|}{$9.000 \mathrm{~kg} \mathrm{ha}^{-1}$} \\
\hline \multirow{3}{*}{$\begin{array}{l}\text { Estimativa dos } \\
\text { parâmetros }\end{array}$} & A 1588,97 & 1915,61 & 1807,63 & 1857,27 & 2029,50 & 2347,64 & 1893,80 \\
\hline & B $-0,099077$ & 0,032525 & $-0,049990$ & 0,078627 & $-0,088988$ & 0,228780 & 0,134094 \\
\hline & C 0,0845 & 0,0646 & 0,08158 & 0,07461 & 0,07419 & 0,06232 & 0,048211 \\
\hline F Regressão & $6073646,4^{* *}$ & $8460482,3^{* *}$ & $7881572,2^{* *}$ & $8036108,9^{* *}$ & $9760615,7 * *$ & $12270660,4 * *$ & $7176764,8^{* *}$ \\
\hline $\mathrm{R}^{2}$ & 0,9901 & 0,9873 & 0,9986 & 0,9985 & 0,9878 & 0,9758 & 0,9876 \\
\hline
\end{tabular}

** Significativo a $1 \%$ de probabilidade.

$\mathrm{Y}=$ quantidade de FD\&C-1 recuperada $(\mu \mathrm{g}) ; \mathrm{X}=$ lâmina de chuva aplicada $(\mathrm{mm}) ; \mathrm{A}$ = assíntota horizontal máxima de extração do traçante $(\mu \mathrm{g}) ; \mathrm{B}=$ deslocamento lateral da curva; e $\mathrm{C}=$ indicativo da velocidade de saída do traçante pela água da chuva. 


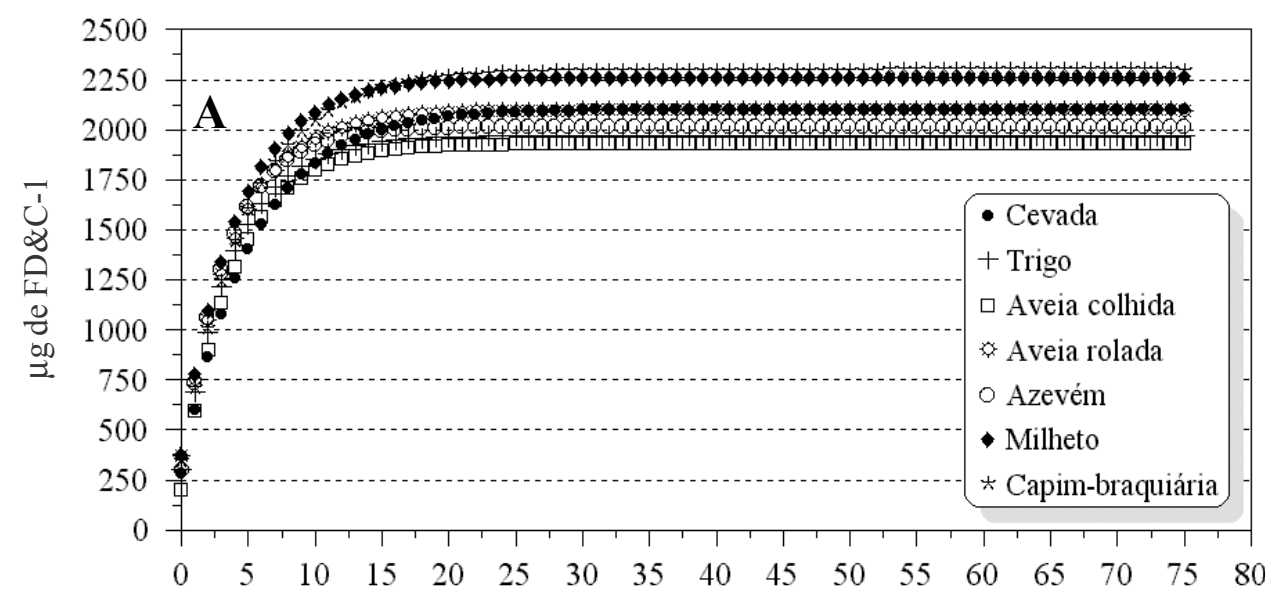

Lâmina de chuva aplicada (mm)

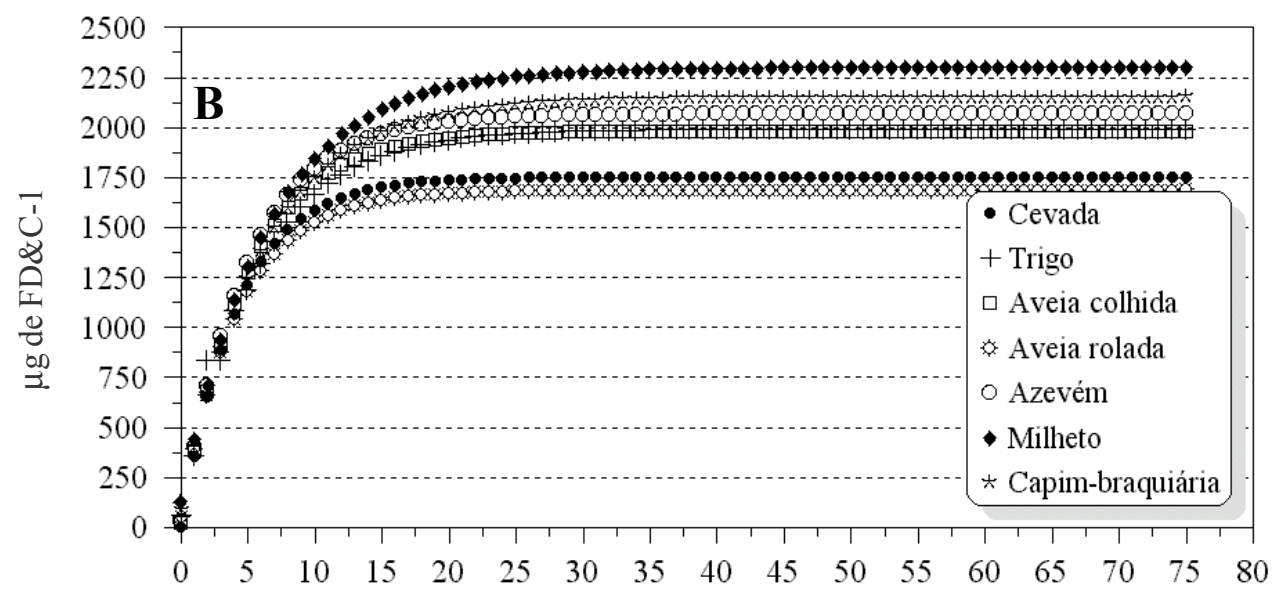

Lâmina de chuva ạplicada (mm)

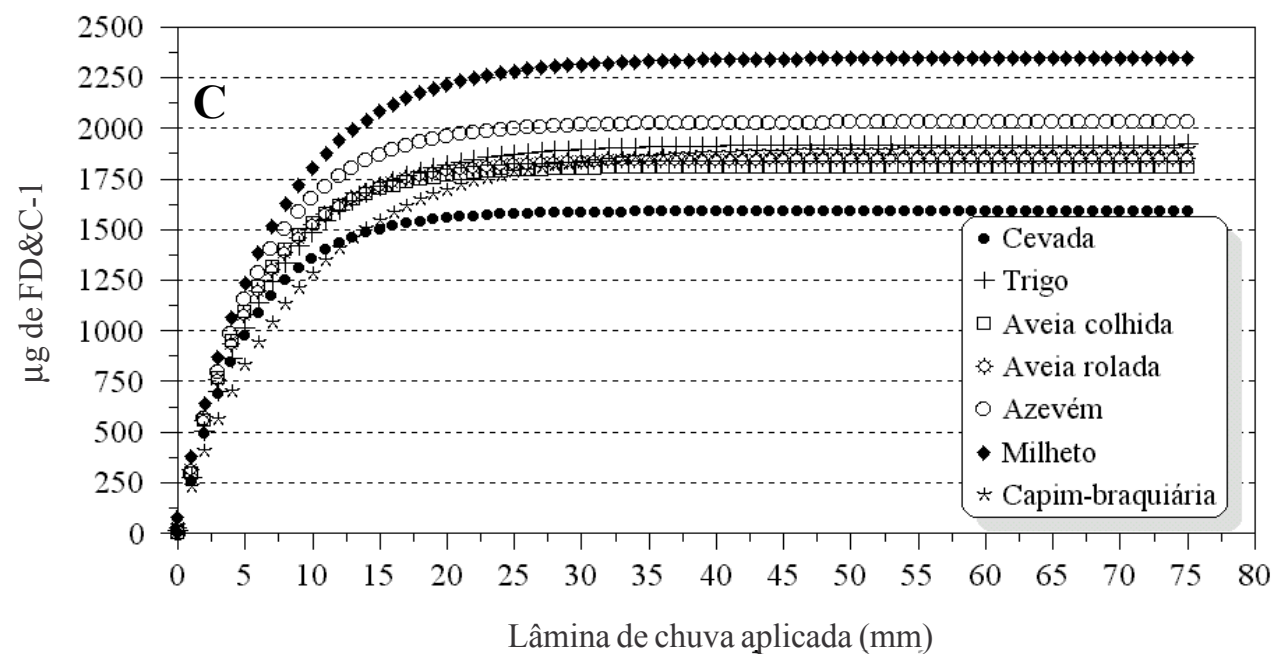

Figura 5 - Equações de regressão entre quantidades de traçante FD\&C-1 ( $\mu \mathrm{g})$ recuperadas em 3.000 (A), 6.000 (B) e 9.000 (C) kg de matéria seca ha ${ }^{-1}$ e lâminas de chuva aplicada artificialmente, utilizando-se o modelo de Mitscherlich. 
Tabela 5 - Quantidade real e porcentagem do traçante FD\&C-1 que transpôs diretamente a palhada formada pelos diferentes tipos e quantidades de resíduos culturais. NuPAM, UNESP/FCA. Botucatu-SP, 2001

\begin{tabular}{|c|c|c|c|c|c|c|}
\hline Parâmetro indicativo & \multicolumn{2}{|c|}{$\mu \mathrm{g}$ de FDC-1 que transpôs diretamente a palha } & \multicolumn{3}{|c|}{ \% de FDC-1 que transpôs diretamente a palha } \\
\hline kg M.S. ha ${ }^{-1}$ & 3.000 & 6.000 & 9.000 & 3.000 & 6.000 & 9.000 \\
\hline Cevada & 240,15 & 18,64 & 9,27 & 10,96 & 1,06 & 0,56 \\
\hline Trigo & 287,34 & 66,57 & 19,13 & 14,43 & 3,25 & 0,95 \\
\hline Aveia colhida & 221,05 & 34,70 & 10,15 & 11,31 & 1,67 & 0,54 \\
\hline Aveia rolada & 357,99 & 74,20 & 22,66 & 16,72 & 4,32 & 1,16 \\
\hline Azevém & 312,13 & 58,74 & 16,40 & 15,43 & 2,74 & 0,78 \\
\hline Milheto & 353,82 & 79,58 & 27,01 & 14,94 & 3,24 & 1,06 \\
\hline Capim-braquiária & 334,47 & 72,55 & 13,97 & 14,27 & 3,21 & 0,70 \\
\hline Média & 300,99 & 57,86 & 16,94 & 14,01 & 2,78 & 0,82 \\
\hline
\end{tabular}

Quanto à facilidade, velocidade ou razão de saída do traçante da palha, indicada pelo parâmetro "c" (Tabela 4), evidenciou-se a redução deste parâmetro com o aumento da quantidade de palha. A única exceção a esse comportamento foi observada para cevada, em que a maior razão de saída foi constatada para $6.000 \mathrm{~kg}$ de palhada ha ${ }^{-1}$.

As quantidades e/ou porcentagens do traçante FD\&C-1 que transpuseram diretamente a palhada somente com a pulverização são representadas na Tabela 5. Para 3.000, 6.000 e $9.000 \mathrm{~kg}$ de palhada $\mathrm{ha}^{-1}$ foram constatadas quantidades médias do total do traçante pulverizado na ordem de 14,01, 2,78 e 0,82\%, respectivamente. Esses resultados evidenciam que, para todas as palhadas a partir de quantidades superiores a $6.000 \mathrm{~kg}$ de matéria seca ha ${ }^{-1}$, somente uma pequena parte da calda pulverizada consegue atravessar a cobertura e atingir a superficie do solo. Em contraste, para recuperação de $50 \%$ do traçante FD\&C-1 aplicado sobre as coberturas de 3.000, 6.000 e $9.000 \mathrm{~kg} \mathrm{ha}^{-1}$, foram necessárias chuvas próximas a 2,50, 3,75 e 3,75 mm, respectivamente.

A análise conjunta dos resultados indica que a quantidade de palhada pouco interfere na facilidade com que o traçante transpõe a camada de resíduos culturais e atinge a superfície do solo. Esse aspecto é importante, considerando as desuniformidades dos pesos pontuais de biomassa observada para diferentes coberturas em campo. Dessa forma, espera-se que quantidades relativamente uniformes do traçante atinjam o solo após precipitações de 10 a $20 \mathrm{~mm}$, independentemente da quantidade de palhada sobre a superfície do solo.

É importante ressaltar a semelhança do comportamento dos diferentes tipos de resíduos culturais quanto à dinâmica de molhamento. Em geral, a maioria dos residuos culturais apresentou comportamento similar de retenção de água da chuva, mesmo quando submetida a diferentes quantidades de cobertura. Esses resultados dão suporte a uma série de questões, principalmente no que diz respeito ao comportamento e funcionamento de herbicidas aplicados em pré-emergência, em sistemas de semeadura direta com cobertura morta. Nessas situações, a água da chuva é o principal e também o único componente responsável pelo transporte desses herbicidas até a superfície do solo.

Portanto, o conhecimento prévio do comportamento supostamente similar da dinâmica de molhamento de diferentes tipos de palhadas possibilita o desenvolvimento de programas de controle de plantas daninhas similares para os diferentes tipos de cobertura, com distintos níveis de irregularidade quanto aos acúmulos de matéria seca por unidade de área.

\section{LITERATURA CITADA}

ALVES, A. G. C.; COGO, N. P.; LEVIEN, R. Relações da erosão do solo com a persistência da cobertura vegetal morta. R. Bras. Ci. Solo, v. 19, p. 127-132, 1995.

BAUMAM, T. T.; ROSS, M. A. Effect of three tillage systems on the persistence of atrazine. Weed Sci., v. 31, p. $423-426,1983$. 
BANKS, P. A.; ROBINSON, E. L. Soil reception and activity of acetochlor, alachlor and metolachlor as affected by wheat (Triticum aestivum) straw and irrigation. Weed Sci., v. 34, p. 607-611, 1986.

BANKS, P. A.; ROBINSON, E. L. The fate of oryzalin applied to straw-mulched and nonmulched soils. Weed Sci., v. 32, p. 269-272, 1984.

CORREIA, N. M.; DURIGAN, J. C. Emergência de plantas daninhas em solo coberto com palha de cana-de-açúcar. Planta Daninha, v. 22, n. 1, p. 11-17, 2004.

DAO, T. H. Subsurface mobility of metribuzin as affected by crop residue placement and tillage method. J. Environ. Qual., v. 24, p. 1193-1198, 1995.

DERPSCH, R. Expansão mundial do plantio direto. R. Plantio Direto, n. 59, p. 32-40, 2000.

EGLEY, G. H.; DUKE, S. Physiology of weed dormancy and germination. In: DUKE, S. O. Weed physiology: I. Reproduction and Ecophysiology. Florida: CRC Press, 1985. p. 27-64.

FORNAROLLI, D. A. et al. Influência da cobertura morta no comportamento do herbicida atrazine. Planta Daninha, v. 16 , p. $97-107,1998$.

GHADIRI, H.; SHEA, P. J.; WICKS, G. A. Interception and retention of atrazine by wheat (Triticum aestivum L.) stubble. Weed Sci., v. 32, p. 24-27, 1984.

GREEN, J. D.; HORTON, R.; BAKER, J. L. Crop residue effects on the leaching of surface-applied chemicals.

J. Environ. Qual., v. 24, p. 343-351, 1995.

LAMOREAUX, R. J.; JAIN, R.; HESS, F. D. Efficacy of dimethenamid, metolachlor and encapsulated alachlor in soil covered with crop residue. Brighton Crop. Protec. Conf. Weeds, v. 3, p. 1015-1020, 1993.

LOCKE, M. A.; BRYSON, C. T. Herbicide-soil interactions in reduced tillage and plant residue management systems. Weed Sci., v. 45, p. 307-320, 1997.

LOMBARDI NETO, F. et al. Efeito da quantidade de resíduos culturais de milho nas perdas de solo e água. R. Bras. Ci. Solo, v. 12, p. 71-75, 1988.

LOPES, P. R. C.; COGO, N. P.; LEVIEN, R. Eficácia relativa de tipo e quantidade de resíduos culturais espalhados uniformemente sobre o solo na redução da erosão hídrica.

R. Bras. Ci. Solo, v. 11, p. 71-75, 1987.
LOWER, S. W.; WEBER, J. B. Atrazine retention by crop residues in reduced-tillage systems. Proc. South Weed Sci. Soc., v. 32, p. 303-307, 1979.

MARIN, C. D. et al. Washoff of herbicides applied to corn residue. Trans. Am. Soc. Agric. Eng., v. 21, p. 1164-1168, 1978.

MARTINS, D. et al. Emergência em campo de dicotiledôneas infestantes em solo coberto com palha de cana-de-açúcar. Planta Daninha, v. 17, n. 1, p. 151-162, 1999.

MEYER, L. D.; WISCHMEIER, W. H.; FOSTER, G. R. Mulches rate required for erosion control on steeps slopes. Proc. Soil Sci. Soc. Am., v. 34, p. 928-931, 1970.

PALLADINI, L. A. Metodologia para avaliação da deposição em pulverizações. 2000. $111 \mathrm{f}$. Tese (Doutorado em Agronomia/Proteção de Plantas) Universidade Estadual Paulista, Botucatu, 2000.

RODRIGUES, B. N. Influência da cobertura morta no comportamento dos herbicidas imazaquin e clomazone. Planta Daninha, v. 11, p. 21-28, 1993.

RODRIGUES, B. N.; LIMA, J.; FORNAROLLI, D. A. Aplicação de trifluralin em pré-emergência sobre diferentes quantidades de cobertura morta no sistema de plantio direto. In: CONGRESSO BRASILEIRO DA CIÊNCIA DAS PLANTAS DANINHAS, 21., 1997, Caxambu. Resumos... Caxambu: Sociedade Brasileira da Ciência das Plantas Daninhas, 1997. p. 365.

RODRIGUES, B. N.; LIMA, J.; YADA, I. F. U. Retenção pela palhada, de herbicidas aplicados em pré-emergência na cultura da soja, em plantio direto. R. Bras. Herb., v. 1, p. $67-72,2000$.

SADE, M. Breve histórico do sistema de plantio direto na palha no Brasil. In: ENCONTRO NACIONAL DE PLANTIO DIRETO NA PALHA, 7., 2000, Foz de Iguaçu. Resumos... Foz de Iguaçu: 2000. p. 15-17.

SIGUA, G. C.; ISENSEE, A. R.; SADEGHI, A. M. Influence of rainfall intensity and crop residue on leaching of atrazine through intact no tillsoil cores. Soil Sci., v. 145, p. 225-232, 1993.

VELINI, E. D.; NEGRISOLI, E. Controle de plantas daninhas em canacrua. In: CONGRESSO BRASILEIRO DA CIÊNCIA DAS PLANTAS DANINHAS, 22., 2000, Foz de Iguaçu. Palestras... Foz de Iguaçu: Sociedade Brasileira da Ciência das Plantas Daninhas, 2000. p. 148-64. 